\title{
CATALYTIC ACTIVITY OF ELECTRODE MATERIALS BASED ON POLYPYRROLE, MULTI-WALL CARBON NANOTUBES AND COBALT PHTHALOCYANINE FOR THE ELECTROOXIDATION OF GLUTATHIONE AND L-CYSTEINE
}

\author{
ANA PORRAS GUTIERREZ 1,2,3,4, MAGDALENA RANGEL ARGOTE ${ }^{5}$, SOPHIE GRIVEAU1,2,3,4*, JOSÉ H. ZAGAL ${ }^{6}$, \\ SILVIA GUTIERREZ GRANADOS ${ }^{5^{*}}$, ALEJANDRO ALATORRE ORDAS ${ }^{5}$ AND FETHI BEDIOUI ${ }^{1,2,3,4}$
}

\author{
1. Chimie ParisTech, Unité de Pharmacologie Chimique et Génétique et Imagerie (UPCGI), 75005 Paris, France. \\ 2. CNRS, UMR 8151, 75005 Paris, France. \\ 3. Université Paris Descartes, 75006 Paris, France. \\ 4. INSERM, U1022, 75005 Paris, France. \\ 5. Universidad de Guanajuato, División de Ciencias Naturales y Exactas, Departamento de Química, Guanajuato, Mexico \\ 6. Universidad de Santiago de Chile, Departamento de Quimica de los Materiales, Facultad de Quimica y Biologia, Casilla 40, \\ Sucursal Matucana, Santiago 9170022, Chile
}

(Received: November 21, 2011 - Accepted: June 12, 2012)

\begin{abstract}
Electrodes prepared from overoxidized pyrrole, multi-walled carbon nanotubes (MWCNT) and cobalt phthalocyanine (CoPc) exhibit a clear catalytic activity for the electrooxidation of L-cysteine and reduced gluthatione. The electrodes are more stable than the ones modified by simple adsorption of CoPc and/or MWCNT. Therefore, these materials offer a good alternative for the development of electrocatalytic applications and thiols detection in biological interest.
\end{abstract}

Keywords: Electrocatalysis, thiols, modified electrodes, carbon nanotubes

\section{INTRODUCTION}

The activation and decomposition of molecules with thiol groups and their derivatives via their electrochemical oxidation is an important topic in industrial and biological research, since these compounds are present as pollutants in fuels [1], and they are used as physiological indicators in biological fluids [2] and as markers of food deterioration [3]. It is known that cobalt phthalocyanines $(\mathrm{CoPc})$ adsorbed on electrode surface or incorporated into polymeric matrices exhibit a pronounced catalytic effect for the electrochemically assisted oxidation of thiols such as cysteine (CySH) and glutathione (GSH) [4-24]. In particular, it has been demonstrated that electrodes modified with electropolymerized CoPc films show superior electrocatalytic activity and greater stability than adsorbed CoPc films [20,25].

When using of phthalocyanine dispersions in polymer matrices $[26,27]$ it is possible to design electrode materials of various features, with improved control of the deposit formed. For example, $4 \mathrm{~b}\left(\mathrm{SO}_{3}{ }^{-}\right) \mathrm{CoPc}$ (tetrasulfonated cobalt phthalocyanine) was incorporated into polypyrrole matrix (PPy) during the polymer oxidation process and a three-dimensional $4 \mathrm{~b}\left(\mathrm{SO}_{3}{ }^{-}\right) \mathrm{CoPc}$ arrangement was thus generated, without altering the electrocatalytic properties of the complex. Moreover, Ozoemena et al. [28] studied the electrosorption of $4 \mathrm{~b}\left(\mathrm{NH}_{2}\right)$ $\mathrm{CoPc}$ (cobalt tetra-aminophthalocyanine) on single wall carbon nanotubes (SWCNT), generating films that are dense and organized with excellent catalytic properties for the oxidation of thiols. Also, Silva et al. [29] reported that electrodes modified with SWCNT and adsorbed CoPc exhibit electrocatalytc activity for the electro-oxidation of 2-ME.

Therefore, it is expected that the combination of CoPc, PPy and multiwalled carbon nanotubes (MWCNT) should generate materials with higher electrocatalytic activity than that corresponding to each of the individual components. The main goal of this study is the preparation and characterization of electrode materials based on glassy carbon electrodes (GCE), CoPc, MWCNT and PPy, with enhanced electrocatalytic activity for the oxidation of L-cysteine and reduced glutathione.

\section{EXPERIMENTAL}

All experiments were performed in a conventional three-electrode electrochemical cell using a GCE disc of $3 \mathrm{~mm}$ diameter (imbedded in Teflon) as the working electrode, a platinum wire as counter-electrode and a $\mathrm{Ag} / \mathrm{AgCl}_{\mathrm{cat}}$ wire as the pseudo-reference electrode The working electrode was polished mechanically using three different sizes of alumina: $1,0.3$ and 0.05 microns, followed by successive rinsing with Milli-Q ultrapure water before each ex- periment. Pyrrole was freshly distilled prior to experiments. MWCNTs were pre-oxidized in a mixture of $\mathrm{H}_{2} \mathrm{SO}_{4} / \mathrm{HNO}_{3}$ as described in the literature [30]. All other chemical products were analytical reagent grade from Sigma-Aldrich and were used without prior purification.

The electropolymerization of pyrrole $(0.1 \mathrm{M})$ was conducted in a solution of $0.1 \mathrm{M} \mathrm{Bu}_{4} \mathrm{NBF}_{4}$ in $\mathrm{CH}_{3} \mathrm{CN}$, applying 10 successive potential sweep cycles between -0.8 and $1.0 \mathrm{~V}$ at $25 \mathrm{mV} \mathrm{s}^{-1}$ [31]. The same electropolymerization conditions were used in the presence of MWCNT $(0.01 \mathrm{mg} / \mathrm{mL})$ and CoPc $(2 \mathrm{mM})$ to prepare the GCE/PPy/MWCNT, GCE/PPy/CoPc and GCE/PPy/MWCNT/ $\mathrm{CoPc}$ electrodes. Once the deposit was generated, the electrode was rinsed several times with $\mathrm{CH}_{3} \mathrm{CN}$ and characterized in a monomer-free supporting electrolyte $\left(0.1 \mathrm{M} \mathrm{Bu}_{4} \mathrm{NBF}_{4}\right.$ in $\left.\mathrm{CH}_{3} \mathrm{CN}\right)$ in a potential window of -0.8 to $1.0 \mathrm{~V}$ at $50 \mathrm{mVs}^{-1}$. The modified electrodes were all submitted to an overoxidation treatment of the polypyrrole to reduce the large capactitive current due to the electrodeposited polypyrrole. This consisted of applying 25 potential sweep cycles in the -0.2 to $1.0 \mathrm{~V}$ potential window at a rate of $50 \mathrm{mV} \mathrm{s}^{-1}$ in a $0.5 \mathrm{M}$ $\mathrm{NaOH}$ solution.

Concentrations ranging from 1 to $5 \mathrm{mM}$ of L-CySH and GSH were used in oxygen-free $0.5 \mathrm{M} \mathrm{NaOH}$ aqueous solutions. These were deoxygenated for 15 minutes with pure $\mathrm{N}_{2}$ before electrochemical experiments. Fresh analyte solutions were prepared before each experiment.

\section{RESULTS}

The GCE/PPy, GCE/PPy/MWCNT and GCE/PPy/CoPc modified electrodes show the typical potentiodynamic features of PPy, nanotubes (MW$\mathrm{CNT})$ and $\mathrm{CoPc}$ in $0.1 \mathrm{M}$ of tetrabutylammonium tetrafluoroborate $\left(\mathrm{Bu}_{4} \mathrm{NBF}_{4}\right)$ in acetonitrile $\left(\mathrm{CH}_{3} \mathrm{CN}\right)$ (Figure 1) [31].

The capacitive current of the modified electrodes is however significant, probably attributed to a larger porosity of the films and increases after the insertion of the various elements into the final material. The enhanced capacitive currents can mask the oxidation signals of the different thiols. However, these enhanced capacitive currents can be diminished if the polypyrrole matrix is overoxidized.

Figure 2 shows the potentiodynamic response of the GCE/PPy/MWC$\mathrm{NT} / \mathrm{CoPc}$ electrode in $0.1 \mathrm{MBu} 4 \mathrm{NBF} 4 \mathrm{CH} 3 \mathrm{CN}$ before (curve a) and after (curve b) the overoxidation of the film in $0.5 \mathrm{M} \mathrm{NaOH}$ in aqueous solution. The capacitive current is drastically reduced and this can be attributed to a loss of the electroactivity of the PPy film $[32,33]$. Nevertheless, overoxidi- 
zed films of GCE/PPy/CoPc, GCE/PPy/MWCNT and GCE/PPy/MWCNT/ $\mathrm{CoPc}$ are still conductive enough to allow the rapid electron transfer of a classical redox couple such as ferri/ferrocyanide. The kinetics of this couple are not affected by overoxidation of the film as shown by cyclic voltammograms compared to bare the GCE, as illustrated on Fig. 1B. It is also noticed from these experiments that the active surface of the modified electrode is almost identical to that of the bare electrode.

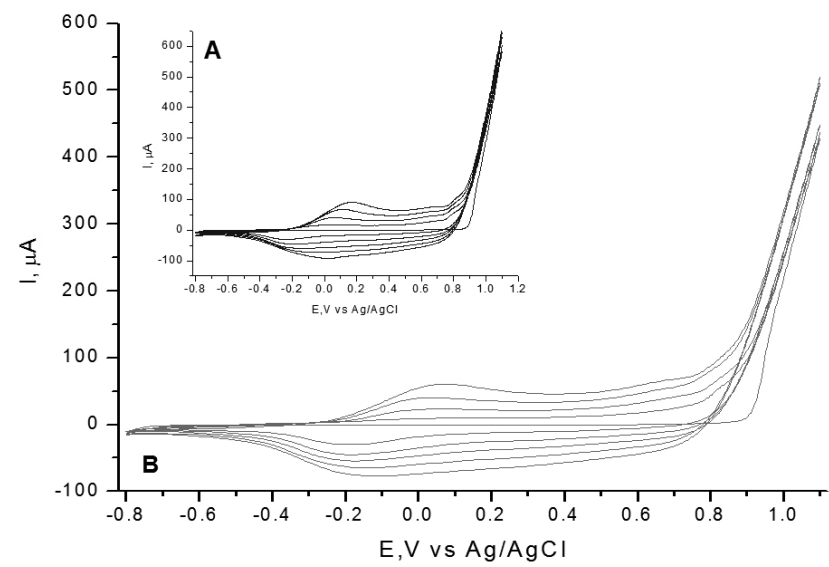

Figure 1.- Cyclic voltammograms for the electropolymerization of $\mathrm{A}$ ) GCE/PPy y B) GCE/PPy/MWNTC/CoPc in $0.1 \mathrm{M} \mathrm{Bu}_{4} \mathrm{NBF}_{4}$ in $\mathrm{CH}_{3} \mathrm{CN}$, (PPy $0.1 \mathrm{M} \mathrm{CoPc} 0.002 \mathrm{M}$ and $0.01 \mathrm{mg} / \mathrm{mL}$ MWNTC) $\mathrm{v}=25 \mathrm{mVs}^{-1}$
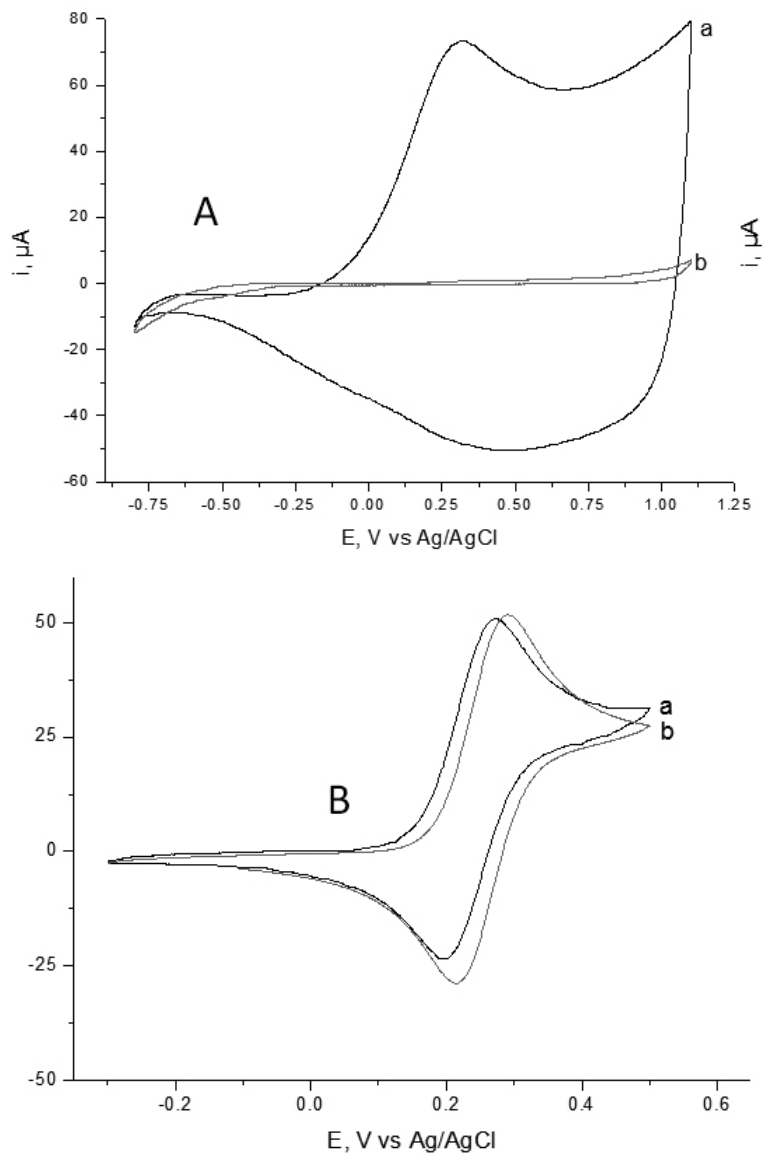

Figure 2. Characterization voltammograms of GCE/PPy/MWCNT/CoPc (a) before and (b) after the overoxidation process, in $0.1 \mathrm{M} \mathrm{Bu}_{4} \mathrm{NBF}_{4}$ in $\mathrm{CH}_{3} \mathrm{CN}$, $\mathrm{v}=50 \mathrm{mVs}^{-1}$. (B) Cyclic voltammogram at (a) bare GC (b) overoxidized GCE/ $\mathrm{PPy} / \mathrm{MWCNT} / \mathrm{CoPc}$ in $5 \mathrm{mM}$ ferrocyanide solution in $0.5 \mathrm{M} \mathrm{NaOH}$.
The electrocatalytic activity of the different modified electrodes was tested for the electro-oxidation of L-CySH and GSH. Figure 3 shows the electrochemical oxidation of (A) L-CySH and (B) GSH (5 mM) on GCE/PPy/MWCNT (curve $i$ ), GCE/PPy/CoPc (curve ii) and GCE/PPy/MWCNT/CoPc (curve iii) in aqueous $0.5 \mathrm{M} \mathrm{NaOH}$ solution. For both L-CySH and GSH, the largest oxidation current is observed with the hybrid electrodes containing $\mathrm{CoPc}$, namely GCE/PPy/CoPc and GCE/PPy/MWCNT/CoPc. This demonstrates that, as expected, $\mathrm{CoPc}$ catalyzes the oxidation of the thiols in the composite electrode. The presence of the MWCNTs inside the electrode material favors the access of the reacting molecules to the active sites of $\mathrm{CoPc}$ within the polymer matrix, leading then to higher oxidation currents.
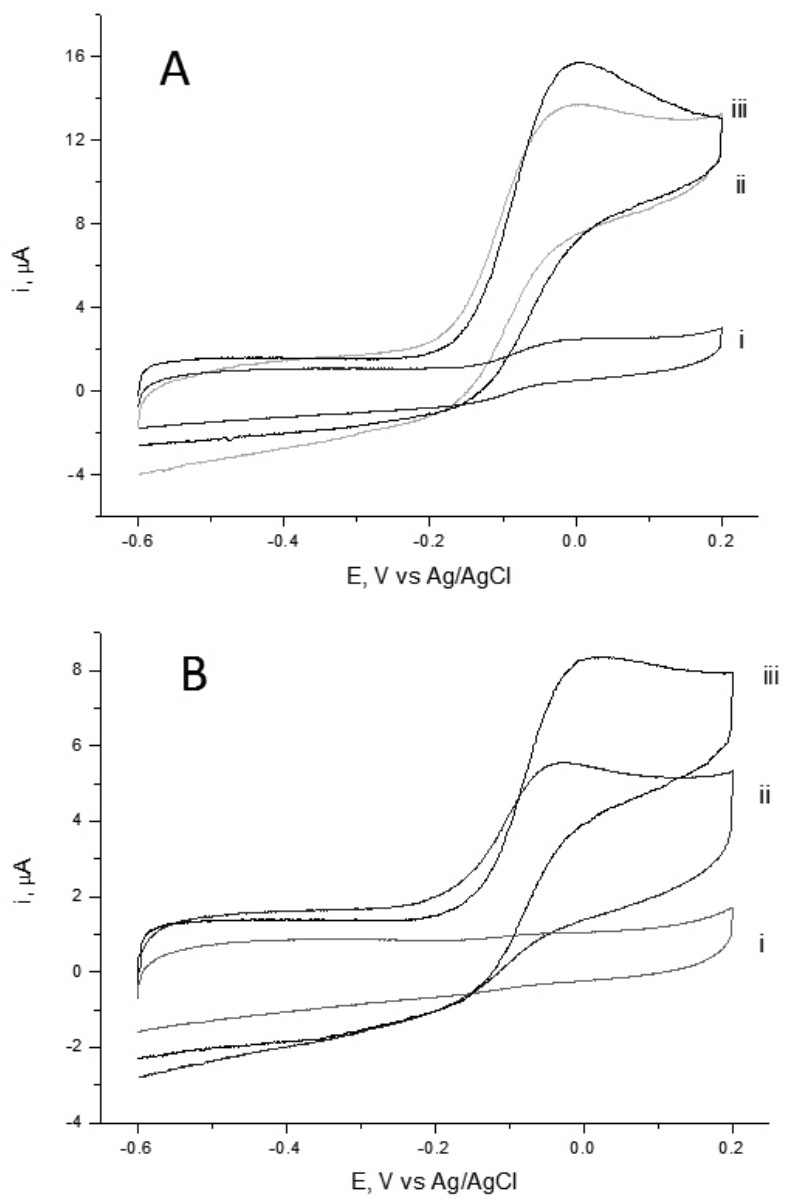

Figure 3. Voltammograms of the oxidation of $5 \mathrm{mM}$ (A) L-CySH and (B) GSH in $0.5 \mathrm{M} \mathrm{NaOH}$ at: (i) GCE/PPy/MWCNT, (ii) GCE/PPy/CoPc and (iii) GCE/PPy/MWCNT/CoPc. $\mathrm{dE} / \mathrm{dt}=50 \mathrm{mVs}^{-1}$

As previously reported and discussed in the literature, the oxidation of thiols in alkaline media most likely involves the formation of a bond between the metal center in the complex and the sulphur atom in the thiolate $[5,8,9,10,14,19]$. The complete reaction scheme is:

$$
\begin{aligned}
& \mathrm{RSH}_{\mathrm{sol}}+\mathrm{OH}^{-} \leftrightarrows \mathrm{RS}_{\text {sol }}^{-}+\mathrm{H}_{2} \mathrm{O} \\
& {[\mathrm{M}(\mathrm{II}) \mathrm{Pc}]_{\text {film }}+\mathrm{RS}_{\mathrm{sol}}^{-} \leftrightarrows \quad[\mathrm{R}-\mathrm{S} \cdots \cdot \mathrm{M}(\mathrm{I}) \mathrm{Pc}]_{\mathrm{film}}^{-}} \\
& {[\mathrm{R}-\mathrm{S} \cdots \mathrm{M}(\mathrm{I}) \mathrm{Pc}]_{\text {film }}^{-} \rightarrow[\mathrm{M}(\mathrm{II}) \mathrm{Pc}]_{\text {film }}+\mathrm{RS}_{\text {sol }}^{-}+\mathrm{e}^{-}} \\
& \mathrm{RS}_{\text {sol }}^{\cdot}+\mathrm{RS}_{\text {sol }}^{\cdot} \rightarrow \mathrm{RS}^{-\mathrm{SR}_{\mathrm{sol}}}
\end{aligned}
$$

Where RSH is thiol, MPc is metallophthalocyanine, and "sol" and "film" stand for species in solution or incorporated to the film on the electrode, respectively. Step 4 is fast and irreversible. A crucial step is step 2, which involves the formation of a Co-S bond, with a partial reduction of the metal center in the catalyst and partial oxidation of the bound thiol molecule. There is evidence by using in-situ reflectance visible spectroscopic for the formation of $\mathrm{Co}(\mathrm{I})$ 
upon interaction of sulfonated $\mathrm{CoPc}$ with L-cysteine [8] on basal plane graphite electrodes. It has been shown that an optimal $\mathrm{Co}(\mathrm{II}) /(\mathrm{I})$ redox potential exists so to obtain the highest activity for the oxidations of thiols in general [19] that would corresponds to an interaction of the thiol in step 2 that is not too weak, not too strong so to favor the catalytic process.

The use of the modified electrodes for the detection of thiols by profiting from the high catalytic activity of $\mathrm{CoPc}$ is exemplified in the case of L-CySH. Figure 4 shows the calibration curves obtained from cyclic voltammetry data for concentrations ranging from 1 to $5 \mathrm{mM}$. A linear correlation is observed with all the modified electrodes examined. The highest sensitivity is obtained with GCE/PPy/MWCNT/CoPc. It is interesting that very low sensitivity is obtained for GCE/PPy/ MWCNT, without CoPc. However, the sensitivity of the modified electrode resulting from the simple adsorption of $\mathrm{CoPc}$ on the MWCNTs is higher than that of all the electrodes. But the analysis of the standard deviation values RSD shows that the electrode modified with adsorbed $\mathrm{CoPc}$ shows lower reproducibility. Indeed, RSD values of $10 \%$ and $2 \%$ were calculated for GCE-adsorbed $\mathrm{CoPc}$ and GCE/PPy/MWCNT/CoPc, respectively. These electrodes show high reproducibility.

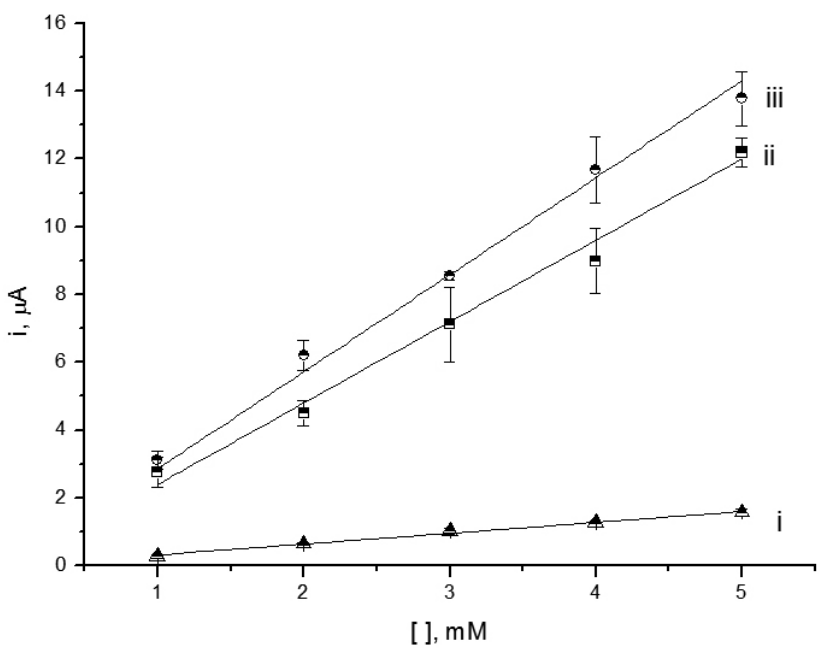

Figure 4. Calibration curves for L-CySH on (i) GCE/PPy/MWCNT , (ii) $\mathrm{GCE} / \mathrm{PPy} / \mathrm{CoPc}$ and (iii) $\mathrm{GCE} / \mathrm{PPy} / \mathrm{MWCNT} / \mathrm{CoPc}$ electrodes (from cyclic voltammetry, at $\mathrm{E}=0 \mathrm{~V}$ )

Table 1 summarizes the analytical performances obtained for the oxidation of L-CySH and Table 2 describes the data for the oxidation of GSH on different electrode materials: sensitivity and limit of detection (LD) and limit of quantification (LQ).

For L-CySH, electrodes prepared by electropolymerization, despite of showing lower sensitivity, offer lower limits of detection and quantification than the electrodes modified by adsorption, with the GCE/PPy/MWCNT/CoPc electrode presenting the lowest $\mathrm{LD}$ and LQ, with values of $0.03 \mathrm{mM}$ and 0.10 $\mathrm{mM}$ respectively. Since L-cysteine is present in cellular concentrations of 200$300 \mu \mathrm{M}$, the GCE/PPy/GCE/PPy/MWCNT, GCE/PPy/CoPc and GCE/PPy/ MWCNT/CoPc.

Table 1. Sensitivity, detection limit and quantification limit values for the detection of L-CySH with the different hybrid electrodes. Data deduced from cyclic voltammetry experiments for L-CySH concentrations ranging from 1 to $5 \mathrm{mM}$.

\begin{tabular}{|l|c|c|c|}
\hline & $\begin{array}{c}\text { Sensitivity, } \\
\boldsymbol{\mu A} / \mathbf{m M}\end{array}$ & LD, $\mathbf{m M}$ & LQ, mM \\
\hline $\mathrm{MWCNT}_{\text {ads }}$ & $1.01 \pm 0.70$ & $0.23 \pm 0.03$ & $0.77 \pm 0.28$ \\
\hline $\mathrm{PPy} / \mathrm{MWCNT}$ & $0.320 \pm 0.001$ & $0.190 \pm 0.002$ & $0.65 \pm 0.02$ \\
\hline $\mathrm{CoPc}_{\text {ads }}$ & $6.74 \pm 0.40$ & $0.140 \pm 0.001$ & $0.470 \pm 0.002$ \\
\hline $\mathrm{PPy} / \mathrm{CoPc}$ & $2.330 \pm 0.002$ & $0.100 \pm 0.001$ & $0.340 \pm 0.004$ \\
\hline $\mathrm{MWCNT/CoPc}$ & $4.00 \pm 0.16$ & $0.040 \pm 0.001$ & $0.130 \pm 0.001$ \\
\hline $\begin{array}{l}\mathrm{PPy} / \mathrm{MWCNT} / \\
\mathrm{CoPc}\end{array}$ & $2.930 \pm 0.001$ & $0.030 \pm 0.001$ & $0.10 \pm 0.02$ \\
\hline
\end{tabular}

For GSH, GCE/PPy/MWCNT/CoPc electrode presenting the lowest LD and LQ, with values $0.02 \mathrm{mM}$ and $0.66 \mathrm{mM}$ respectively. These electrodes are good candidates as voltammetric sensors for biological samples

Table 2. Sensitivity, detection limit and quantification limit values for the detection of GSH with the different hybrid electrodes. Data deduced from cyclic voltammetry experiments for GSH concentrations ranging from 1 to $5 \mathrm{mM}$.

\begin{tabular}{|l|c|c|c|}
\hline & $\begin{array}{c}\text { Sensitivity, } \boldsymbol{\mu A} / \\
\mathbf{m M}\end{array}$ & LD, $\mathbf{m M}$ & LQ, $\mathbf{~ M M}$ \\
\hline $\mathrm{MWNTC}_{\text {ads }}$ & $0.63 \pm 0.30$ & $0.24 \pm 0.02$ & $0.82 \pm 0.24$ \\
\hline $\mathrm{PPy} / \mathrm{MWNTC}$ & 0.037 & 1.66 & 5.55 \\
\hline $\mathrm{CoPc}_{\text {ads }}$ & $3.25 \pm 0.83$ & $0.25 \pm 0.04$ & $0.83 \pm 0.48$ \\
\hline $\mathrm{PPy} / \mathrm{CoPc}$ & $0.89 \pm 5 \times 10^{-3}$ & $0.22 \pm 5 \times 10^{-3}$ & $0.75 \pm 0.04$ \\
\hline $\mathrm{MWNTC/CoPc}$ ads & $2.22 \pm 0.48$ & $0.21 \pm 0.02$ & $0.70 \pm 0.21$ \\
\hline $\begin{array}{l}\mathrm{PPy} / \mathrm{MWNTC} / \\
\mathrm{CoPc}\end{array}$ & $1.15 \pm 4 \times 10^{-3}$ & $0.20 \pm 1 \times 10^{-4}$ & $0.66 \pm 2 \times 10^{-3}$ \\
\hline
\end{tabular}

\section{CONCLUSION}

It can be concluded that modified electrodes prepared from overoxidized pyrrole, MWCNT and CoPc exhibit a clear catalytic activity for the electro-oxidation of L-cysteine and reduced glutathione. These electrodes exhibit lower detection limits and are more stable than the electrodes modified by simple adsorption of $\mathrm{CoPc}$ on the MWCNT. Therefore, these materials could be a good alternative for the development of electrochemical sensors for thiols of biological interest.

\section{ACKNOWLEDGEMENTS}

Financial supports from CNRS (PICS n ${ }^{\circ} 5738$ (2011-2013), France), Chimie Paris Tech (J.H.Z Professeur Invité), FONDECYT- 1100773, "Financiado por ICM con aportes del Fondo de Innovación para la Competitividad, del Ministerio de Economía, Fomento y Turismo Project P07- 006-F". (Chile), CONACYT and Universidad de Guanajuato (Mexico) are acknowledged.

\section{REFERENCES}

1. B. Basu, S. Sathapathy, A. K. Bhatnagar A K., Catal. Rev. Sci. Eng. 35, 571 (1993)

2. T. R. Ralph, M. L. Hitchman, J. P. Millington, F. C. Walsh, J. Electroanal. Chem. 375, 1 (1994)

3. P. M. Schweizer-Bewrberich, S. Vaihinger, W. Gopel, Sensors and Actuators $B$ 18, 282 (1994)

4. J. Zagal, C. Fierro, R. Rozas, J. Electroanal. Chem. 119, 403 (1981)

5. J. Zagal, P. Herrera, Electrochim.Acta, 30, 449 (1985)

6. C. Páez, A. Prelle, S. Ureta-Zañartu, J. Zagal, Bol. Soc. Chil. Quím., 35 299 (1990)

7. J. H. Zagal, Coord.Chem.Revs 119, 89 (1992)

8. R.O Lezna, S. Juanto, and J.H. Zagal J. Electroanal. Chem., 452, 221 (1998)

9. J.H. Zagal, M. Gulppi, M. Isaacs, G. Cárdenas and M.J. Aguirre, Electrochim. Acta, 44, 1349 (1998)

10. J. H. Zagal, S. Griveau, F. Silva, T. Nyokong, F. Bedioui, Coord. Chem. Rev. 254, 2755 (2010)

11. J. H. Zagal, M. A. Gulppi, C. A. Caro, G. I. Cárdenas-Jirón, Electrochem. Commun. 1, 389 (1999)

12. J. H. Zagal J H, M. A. Gulppi, G. I. Cárdenas-Jirón, Polyhedron 19, 2255 (2000)

13. J.H. Zagal and J.J.H.Henríquez, Bol. Soc. Chil. Quím. 45, 237 (2000).

14. G. I. Cárdenas-Jirón, M. A. Gulppi, C. A. Caro, R. del Río, M. Páez, J. H. Zagal, Electrochim. Acta 46, 3227 (2001)

15. S. Griveau, V. Albin, T. Pauporté, J. H. Zagal, F. Bedioui, J. Mater. Chem. 12, 225 (2002)

16. S. Griveau, M. Gulppi, J. Pavez, J. H. Zagal, F. Bedioui, Electroanalysis 15, 779 (2003)

17. N. Sehlotho, T. Nyokong, J. H. Zagal, F. Bedioui, Electrochim. Acta 51, 5125 (2006)

18. N. Pereira-Rodrigues, R. Cofré, J. H. Zagal, F. Bedioui, Biolelectrochem. 70, 147 (2007) 
19. F. Bedioui, S. Griveau, T. Nyokong, A. J. Appleby, C. A. Caro, M. Gulppi, G. Ochoa, J. H. Zagal Phys. Chem. Chem. Phys. 9, 3383 (2007)

20. S. Griveau, J. Pavez, J. H. Zagal, F. Bedioui, J. Electroanal. Chem. 497, 75 (2001)

21. R. C. Luz, F. S. Damos, A. A. Tanaka, L. T. Kubota, Y. Gushikem. Talanta $761097(2008)$

22. R.C. S. Luz, C. M. Maroneze, A. A. Tanaka, L.T. Kubota, Y. Gushikem, F. S. Damos Microchim Acta 171, 169 (2010)

23. M.J. Aguirre, M. Isaacs, F.Armijo, J.H. Zagal, Electroanalysis, 14, 356 (2002)

24. C. Gutiérrez, J. F. Silva, J. Pavez, F. Bedioui, J. H. Zagal, Electrocatalysis ,3, $153(2012)$

25. M. K. Halbert, R. P. Baldwin, Anal. Chem. 57, 591 (1985)
26. B. A. Retamal, M. E. Vaschetto, J. H. Zagal, J. Electroanal. Chem. 431, 1 (1997)

27. M. Gulppi, F. Bedioui, J. H. Zagal, Electroanalysis 13, 1136 (2001)

28. K. I. Ozoemena, J. Pillay, T. Nyokong, Electrochem. Commun. 8, 1391 (2006)

29. J. F. Silva, S. Griveau, C. Richard, J. H. Zagal, F. Bedioui, Electrochem. Commun. 9, 1629 (2007)

30. J. Liu, A. G. Rinzler, H. Dai, J. H. Hafner, R. K. Bradley, J. Boul, A. Lu, T. Iverson, T. Shelimov, C. B. Huffman, F. Rodriguez-Macias, Y.-S. Shon, T. R. Lee, D. T. Colbert, R. E. Smalley, Science, 280, 1253 (1998)

31. M. Zhou, J. Heinze, J. Phys. Chem. B, 103, 8451 (1999)

32. Z. Gao, J. Electroanal. Chem. 373, 141 (1994)

33. T. F. Otero, M. Márquez, I. Suárez, J. Phys. Chem. B 108, 15429 (2004) 